\title{
Association between Influenza during Pregnancy and Childhood Leukaemia
}

\author{
TIMO HAKUULINEN, LIISA HOVI， MARKETTA KARKINEN-JÄÄSKELÄINEN, KARI PENTTINEN, \\ LAURI SAXÉN
}

British Medical fournal, 1973, 4, 265-267

\section{Summary}

This report based on the data available from the Finnish Cancer Registry and from virus isolations gives further support to the association $(P=0.04)$ between maternal influenza of the 1957 "Asian" type and subsequent later leukaemia in the infants. No such association was found from other influenza epidemics.

\section{Introduction}

The report of a positive association between maternal influenza during pregnancy and subsequent leukaemia in the child (Fedrick and Alberman, 1972) has been confirmed by another epidemiological study (Bithell et al., 1973). On the other hand, an analysis stimulated by the original finding failed to show this association in another English population (Leck and Steward, 1972). Clearly the problem calls for further analysis, and this need prompted the present study of a Finnish population, from which we believe adequate data are available for testing the Fedrick-Alberman association. Our findings provide further evidence of an association between maternal influenza of the 1957 "Asian" type and subsequent later leukaemia of the infants, whereas analysis of other influenza epidemics has not shown any such association.

\section{Source of Information}

The following sources were available for estimations of influenza epidemics in Finland and for the determination of possible annual or seasonal fluctuations in the incidence of childhood malignancies.

Central Bureau of Statistics. - The exact number of stillbirths and livebirths are available on both a regional and monthly basis.

Finnish Cancer Registry.-A nationwide, compulsory registration of neoplastic diseases has been in force since 1953 and the data are collected from notification cards, hospital and laboratory records, and death certificates (Saxén et al., 1969). In addition to the type of disease the records of the registry provide the date of birth of the patients and the date and basis of their diagnoses. All cases of leukaemia recorded in children under the age of 10 and born in the years 1953-9 are included.

Finnish Cancer Registry, Helsinki, Finland

TIMO HAKULINEN, M.A., Statistician

Department of Virology, University of Helsinki, Finland

LIISA HOVI, M.D., Research Assistant

KARI PENTTINEN, M.D., Professor of Virology

Third Department of Pathology, University of Helsinki, Finland

MARKETTA KARKINEN-JÄÄSKELÄINEN, M.D., Research Assistant LAURI SAXÉN, M.D., Professor of Experimental Pathology
Records of Central Public Health Laboratory and Department of Virology, University of Helsinki.-During the study period (1953-9) all virus isolations in Finland were performed by these two institutes and their files thus contribute the sole source of information concerning the time and type of virus isolations in the country.

Absenteeism Registry of District of Helsinki.-A registration system was devised in 1952 for continuous monitoring of employees' absenteeism in a number of factories, institutions, and governmental enterprises in the Helsinki district. The Registry, which during the 1960 s covered some $30,000 \mathrm{em}-$ ployees, gives a satisfactory idea of the sickness absenteeism of a representative sample of the Helsinki population, and shows a remarkably stable "background" of absenteeism, slightly below $1 \%$. The increase in this figure seems to correlate well with influenza epidemics when compared to other criteria for the latter (virus isolations, reports of infectious diseases, hospital statistics, etc.). The common course of an epidemic in Finland is that it fades out, even in remote parts of, the country within three months after the start in Helsinki in Southern Finland.

\section{Influenza Epidemics in Finland 1953 to 1959}

Based on information collected from the above sources, six epidemics of influenza could be identified during the study period 1953-9 (table I). By using the absenteeism figures for Helsinki (representing one-fifth of the total population) and assuming that the mean period of influenza absenteeism was of the order of six days and the "normal" sickness absenteeism of the order of $1 \%$, the morbidities of the different epidemics were calculated from the absenteeism peaks. For the 1957 Asian influenza epidemic other sources of morbidity information (Kaipainen and Ohela, 1959; Saxén et al., 1961) gave a morbidity estimate corresponding well with the estimate calculated from the absenteeism figures.

TABLE I-Estimates of Influenza Epidemics in Finland between 1953 and 1960 and Virus Isolation Data from Same Period "Period of Epidemic" gives First and Last Days of "Normal" Background Absenteeism

\begin{tabular}{|c|c|c|c|c|}
\hline Year & $\begin{array}{l}\text { Period of } \\
\text { Epidemic }\end{array}$ & $\underset{\text { Pbsenteeism }}{\text { Peak }}$ & $\begin{array}{l}\text { Estimated } \\
\text { Morbidity }\end{array}$ & $\begin{array}{l}\text { Strain of Influenza } \\
\text { Virus Isolated }\end{array}$ \\
\hline $\begin{array}{l}1952 \\
1953 \\
1954 \\
1955 \\
1956 \\
1957\{ \\
1958 \\
1959 \\
1960\end{array}$ & $\begin{array}{l}28 / 1-11 / 3 \\
21 / 1-9 / 3 \\
23 / 3-4 / 5 \\
28 / 9-7 / 12 \\
12 / 4-17 / 5 \\
5 ! 12-20 / 2 \\
-20 / 2\end{array}$ & $\begin{array}{r}5 \cdot 4 \\
2 \cdot 4 \\
2 \cdot 2 \\
10 \cdot 0 \\
2 \cdot 0 \\
2 \cdot 4\end{array}$ & $\begin{array}{r}18 \cdot 0 \\
4 \cdot 9 \\
2 \cdot 9 \\
30 \cdot 0 \\
3 \cdot 4 \\
5 \cdot 3\end{array}$ & $\begin{array}{l}\mathbf{A}_{1} \text { (Liverpool) } \\
\mathrm{A}_{1} \text { - } \\
\mathrm{B}_{1} \\
\mathrm{~A}_{1} \text { (Netherlands) } \\
\mathrm{A}_{1} \text { (Netherand) } \\
\mathrm{A}_{2} \text { (Singapore) } \\
\mathrm{A}_{2} \text { (Singapore) } \\
\mathrm{A}_{2} \text { (Singapore) }\end{array}$ \\
\hline
\end{tabular}

\section{Material}

Altogether, 610,733 livebirths were registered in Finland in the years 1953-9. Of these, children with leukaemia of the lymphatic and haematopoietic system (International Classification of 
Diseases, 7th rev., code 204) were included in the study. The data relating to their births had been recorded. According to the original findings of Fedrick and Alberman (1972) the development of malignancy showed no association with the stage of pregnancy when the mother contracted influenza. Consequently the subjects were divided into the following four groups.

(1) Children Born during an Epidemic.-The epidemic was estimated to last for no more than three months after the isolation of the virus, and consequently the four calendar months involved were thought to represent the "epidemic" proper. During this period a proportion but not all of the mothers could have been exposed to the disease. Hence, none were included in the study and control groups.

(2) Children Born during First Five Months after an Epidemic.In this actual study group all mothers-to-be had a risk of contracting influenza during the epdiemic.

(3) Children Born in Sixth to Ninth Postepidemic Month.Only a small proportion of the mothers in this group could have been exposed to the virus during the actual epidemic and hence they were excluded both from the study and the control groups.

(4) Children Born more than Nine Months after End of Epidemic and before Outbreak of Next Influenza Epidemic.-This group of children born to unexposed mothers constitutes the control group.

\section{Method}

The arc sin transformed (Hald, 1952) incidence of childhood leukaemia in the study group was compared with that in the control cohort. The risk ratio was estimated according to the method of Leck and Steward (1972) as follows: where the risk to a child of a mother not exposed to influenza is $\mathrm{p}_{\mathrm{n}}$, and the risk to a child of an exposed mother is $p_{i}$, then the following equation is valid:

$$
\text { (1) } L=(1-c) s p_{n}+c s p_{i}
$$

where $s$ is the number of children born during the study period, $\mathrm{L}$ the number of cases with leukaemia born during that period, and $c$ the morbidity of the epidemic. When $p_{n}$ was known, $p_{i}$ and consequently the ratio $\mathrm{p}_{\mathrm{i}} / \mathrm{p}_{\mathrm{n}}$ could be determined from equation (1). Finally, the data were tested for compatibility with true postinfluenza risks $\mathrm{p}_{\mathrm{i}}$ of 2,3 , and 4 times the observed values of $\mathrm{p}_{\mathrm{n}}$. The observed leukaemia incidence (among children) in the study group was compared with their predicted values, assuming that the number of cases followed a Poisson distribution.

\section{Results}

The material from 1953-9 was treated in two stages. Firstly, all recorded epidemics were pooled and their study periods compared to a pooled control group. The incidence of leukaemia in the pooled groups 1 to 4 and in the Asian group is shown in table II.

TABLE II-Incidence of Leukaemia (International Classification of Diseases No. 204) in Different Groups of Children, Followed over 10 Years

\begin{tabular}{|c|c|}
\hline Study Group & $\begin{array}{c}\text { Incidence } \\
(0) \\
0\end{array}$ \\
\hline $\begin{array}{l}\text { 1-Children born during the } 1953-62 \text { epidemics } \\
\text { 2-Children born during the subsequent five months } \\
\text { 3-Children born in the sixth to the ninth month after epidemic } \\
\text { 4-Children born during the control periods } \\
\text { Children born during the } 1958 \text { study period (Asian influenza) }\end{array}$ & $\begin{array}{l}45 \cdot 1 \\
43 \cdot 7 \\
39 \cdot 4 \\
44 \cdot 2 \\
68 \cdot 1\end{array}$ \\
\hline
\end{tabular}

Seventy-nine cases of leukaemia were found in the study group of 180,862 children (group 2, table II), and the figure did not differ significantly from the 100 cases of leukaemia found in the 226,308 controls. The equation (1) gave a risk ratio estimate of 0.90 . The observed incidence was compatible with the theoretical numbers of cases resulting from risk ratios 1 and 2 but not that of 3 (significance $5 \%$ ) or $4(1 \%)$. If we had assumed that the mean period of influenza absenteeism had been four or five days the observed incidence would have been compatible and incompatible with the same theoretical numbers as with the six days' assumption. With a seven or eight days' assumption the only change would have been the inability to show any incompatibility between the observed incidence and the theoretical numbers resulting from the risk ratio 3 .

Since no association was found the 1957 Asian influenza epidemic data were extracted from the records and compared with that of the controls.

During the study period of the 1957 Asian influenza epidemic (January-May 1958) 35,248 livebirths were recorded of which 24 developed leukaemia during a 10-year follow-up. The control group consisted of 226,308 children born after unexposed periods between 1953 and 1959, and in 100 of these leukaemia was reported. The corresponding incidence figures were $68 \cdot 1 / 10^{5}$ and $44 \cdot 2 / 10^{5}$, the former being higher at the significance level of $\mathbf{P}=0.048$. When compared to the corresponding incidence for the entire study material, excluding the 1957 study group $\left(42 \cdot 1 / 10^{5}\right)$, the difference was significant at the level $\mathrm{P}=0 \cdot 040$. The value for $\mathrm{p}_{i}$ calculated from equation (1) was $123.9 / 10^{5}$ and the risk ratio $\mathrm{p}_{\mathrm{i}} / \mathrm{p}_{\mathrm{n}}$ was 2.80 when the influenza rate was taken as $c=0.30$ (Kaipainen and Ohela, 1959; Saxén et al., 1961). The absenteeism figures were therefore not used. The observed incidence was compatible with the theoretical number of cases resulting from the risk ratios 1 to 5 but not that of the ratio 6 (significance $5 \%$ ) or $7(1 \%)$. The effect of the morbidity (c) (attack rate) on these estimations is shown in the graph.

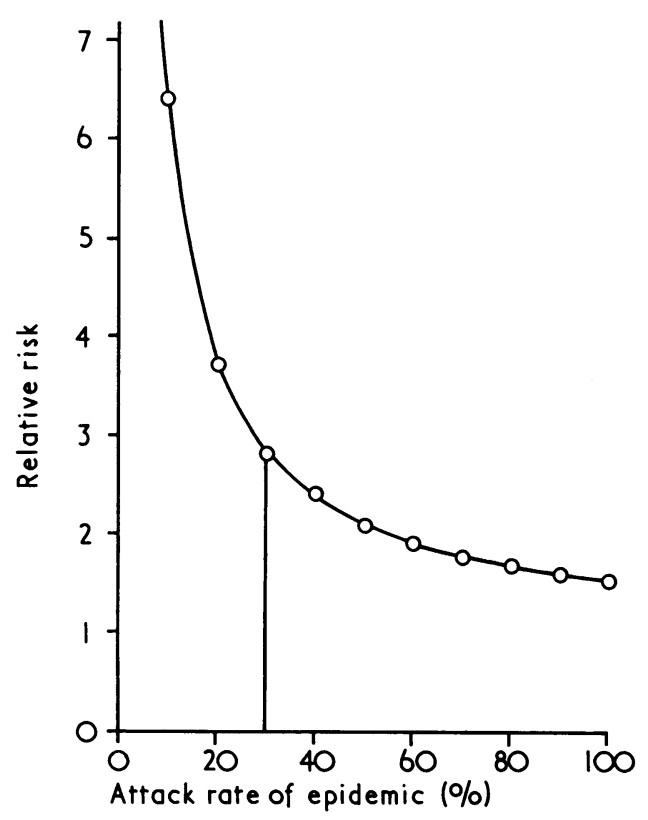

Association between maternal influenza and childhood leukaemia: relative risk of leukaemia during first 10 years of life as a function of an influenza epidemic during pregnancy. Estimation based on data related to 1957 "Asian" influenza epidemic in Finland (attack rate (morbidity) about $30 \%$ ).

\section{Discussion}

This analysis supports the hypothesis that the 1957 Asian influenza epidemic correlates with the occurrence of leukaemia in children who were exposed in utero to the infection (or to factors contingent on the disease). Our study failed to show 
similar associations between other influenza epidemics and childhood leukaemia.

If the correlation shown by Fedrick and Alberman (1972) and supported by Bithell et al. (1973) and our study reflects a true causal relationship it is certainly premature to attribute this to the virus. We have previously emphasized the possible significance of heavy medication, correlating with influenza and teratogenesis (Hakosalo and Saxén, 1971; Karkinen-Jääskeläinen and Saxén, 1973), and there could be carcinogens among these drugs. On the other hand, it is then difficult to explain the uniqueness of the 1957 epidemic caused by the $A_{2}$ virus on this basis.

However, present knowledge of the variation of influenza A viruses shows that a profound alteration in the properties of the haemagglutinating and neuraminidase subunits of the influenza virion surface (Webster and Laver, 1972) occurs once in 10 to 30 years. This happened in 1957.

The alteration is characterized by a new antigenicity of both subunits. When the so-called Hong Kong variant appeared in 1969 analysis of tryptic peptides of the haemagglutinating proteins showed extensive alterations in its amino-acid sequence, indicating that substitution in the molecules had occurred (Webster and Laver, 1972). This is thought to be brought about by recombination within the genomes of different influenza viruses from different animal species, particularly avian and swine strains. New genetic information, unrelated to the influenza genome, may be transferred by recombinant strains to the human population. In some cases this information may traverse the placental barrier and reach the developing fetus, though viraemia in influenza and transfer through the placenta is thought to be rare (Monif et al., 1973).
The appearance of a "new" influenza virus against which few or no antibodies exist anywhere in the world results in a highly contagious pandemic and possibly increased severity of the disease and its consequences. The latter may be observed as an increased mortality among some age groups, increased production of congenital malformations, and an increased rate of pneumonia and encephalitic syndromes. Not all the factors have been studied but the possibility of increased leukaemia incidence in children born to mothers who have had influenza during pregnancy is of special interest.

\section{References}

Bithell, J. F., Draper, G. J., and Gorbach, P. D. (1973). British Medical Fournal, 1,706 .

Fedrick, J., and Alberman, E. D. (1972). British Medical fournal, 2, 485.

Hakosalo, J., and Saxén, L. (1971). Lancet, 2, 1346. Hald, A. (1952). Statistical Theory with Engineering Applications. New York,

Karkinen-Jääskeläinen, M., and Saxén, L. (1973). American fournal of Obstetrics and Gynecology, In press.

Leck, I., and Steward, J. K. (1972). British Medical fournal, 4, 631.

Monif, G. R., Sowards, D. L., and Eitzman, D. V. (1973). American fournal of Obstetrics and Gynecology, 114, 239.

Kaipainen, W. J., and Ohela, K. (1959). Annales Medicinae Internae Fenniae, 48,77

Saxén, E., Hakama, M., and Lehtonen, M. (1969). Annals of Clinical Research, 1, 291

Saxén, L., Hjelt, L., Sjöstedt, J. E., Hakosalo, J., and Hakosalo, H. (1960). Acta Pathologica et Microbiologica Scandinavica, 49, 114.

Webster, R. G., and Laver, W. G. (1972). Bulletin of the World Health Organization, 47, 449.

\title{
Blood Lead Levels in a Welsh Rural Community
}

\author{
W. H. BEASLEY, \\ D. D. JONES, \\ A. MEGIT, \\ SYLVIA G. LUTKINS
}

\section{Introduction}

The poisonous properties of lead in excessive amounts have long been recognized. Accidental ingestion, particularly in children, has produced serious disease. It was one of the first metals to be used by man and there has been extensive exploitation to obtain it. Present in air, food, and water, lead is inevitably absorbed by man. It is not an element which is necessary for human metabolism, but whether its presence in the body causes any ill effects in people not exposed to lead industrially is disputed. One of the points of dispute is its so-called "normal" range in blood.

Kehoe et al. (1935) in the U.S.A. reported a mean blood lead level of $58 \mu \mathrm{g} / 100 \mathrm{ml}$ (S.D. $21 \mu \mathrm{g}$ ) in 71 medical students, and Kehoe et al. (1940) one of $25 \mu \mathrm{g} / 100 \mathrm{~g}$ (S.D. $5 \mu \mathrm{g}$ ) in 30 normal Americans and 30 normal Mexicans. Horiuchi and Takada (1954) found in $95 \%$ of $\mathbf{4 4}$ normal Japanese that the blood lead level was less than $31 \mu \mathrm{g} / 100 \mathrm{~g}$ and Patterson (1965), from the U.S.A., reported a range of $5-40 \mu \mathrm{g} / 100 \mathrm{ml}$. The U.S. Department of Health (1965) reported that in 2,342 people only 11 had a concentration exceeding $60 \mu \mathrm{g} / 100 \mathrm{ml}$. Goldwater and Hoover (1967) found a range of $15-40 \mu \mathrm{g} / 100 \mathrm{ml}$ in blood lead levels of 829 people from 16 countries. They added that the levels in New Guinea aborigines were comparable to those in people living in industrialized countries. After an investigation of the blood lead levels of 689 people living in the U.S.A., South America, Africa, and New Guinea, Stopps (1968) reported a range of 13-23 $\mu \mathrm{g} / 100 \mathrm{~g}$. Kubota et al. (1968) found in 243 healthy Americans a range of $7 \cdot 25-20.34 \mu \mathrm{g} / 100 \mathrm{ml}$, and the level of blood lead depended on where in the U.S.A. the subject lived. 